\begin{tabular}{|l|l|}
\hline Conceptos clave para la formación & $\begin{array}{l}\text { Francisco Javier Gutiérrez-Ruiz } \\
\text { Julio Frías Peña }\end{array}$ \\
Gestión y diseño industrial \\
p. [173]-207 \\
En: \\
Gutieñador Industrial \\
Conceptos clave para la formación del Diseñador \\
Industrial. Ciudad de México: Universidad Autónoma \\
Metropolitana, Unidad Azcapotzalco, 2012. 312 páginas. \\
Fuente: ISBN 978-607-477-626-3 \\
Relación: \\
http://hdl.handle.net/11191/7663 \\
https://doi.org/10.24275/uama.352.7663
\end{tabular}

\begin{tabular}{|c|c|c|}
\hline $\begin{array}{c}\text { Universidad } \\
\text { Mutónoma } \\
\text { Metropolitana }\end{array}$ Casa abierta al tiempo Azcapotzalc & $\begin{array}{l}\text { División de Ciencias y Artes para } \\
\text { el Diseño } \\
\text { https://www.cyad.online/uam/ }\end{array}$ & $\begin{array}{l}\text { Devaluación } \\
\text { Del diseño en el tiempo } \\
\text { http://evaluacion.azc.uam.mx/ } \\
\text { Tiempo }\end{array}$ \\
\hline 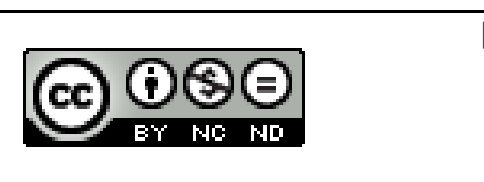 & \multicolumn{2}{|c|}{$\begin{array}{c}\text { Excepto si se señala otra cosa, la licencia del ítem se describe como } \\
\text { Atribución-NoComercial-Sin Derivadas } \\
\text { https://creativecommons.org/licenses/by-nc-nd/4.0/ }\end{array}$} \\
\hline
\end{tabular}

D.R. (C) 2012. Universidad Autónoma Metropolitana. Unidad Azcapotzalco (UAM Azcapotzalco). Se autoriza copiar y redistribuir el material en cualquier medio o formato, siempre y cuando se den los créditos de manera adecuada, no puede hacer uso del material con propósitos comerciales, si remezcla, transforma o crea a partir del material, no podrá distribuir el material modificado. Para cualquier otro uso, se requiere autorización expresa de la UAM Azcapotzalco. 
DOI: 10.24275/uama.7048.7675

CONCEPTOS DESARROLLADOS

- Actores sociales y diseño industrial

- Capacidad de la empresa para innovar

- Cultura de desarrollo

- Diferenciación de productos

- Entorno empresarial

- Gestión del diseño industrial

- Innovación y competitividad

- Planeación

- Toma de decisiones en diseño 
DOI: 10.24275/uama.7048.7675

DESARROLLO DE CONCEPTOS POR:

DI. Francisco Javier Gutiérrez Ruíz

Profesor-investigador del Departamento

de Evaluación del Diseño en el Tiempo,

División CyAD, UAM/Azc.

DR. Julio Frías Peña

Profesor del Departamento de Arquitectura,

División de Ingeniería y Arquitectura, ITESM,

Campus ciudad de México 


\section{Gestión y diseño industrial}

La sociedad contemporánea, como se sabe, fluye a través de las organizaciones, entendidas éstas como "unidades sociales deliberadamente construidas para alcanzar fines específicos" (Rodríguez, 2001:28). Por supuesto, estos fines organizacionales en su conjunto tienden a satisfacer las diversas necesidades de una sociedad plural y cambiante y se llevan a la práctica a través de iniciativas de carácter gubernamental, privado y ciudadano, en pro de un desarrollo equilibrado.

En el caso de los nuevos productos y servicios, algunas de las organizaciones que participan en el proceso se muestran como actores decisivos para el diseño industrial, principalmente porque reconocen en el cambio un recurso esencial del desarrollo, pero además, porque tienen el poder y la capacidad para inducirlo y concretarlo socialmente. Es en este sentido que crece el reconocimiento al diseñador, ante una necesidad primordial local: generar iniciativas de cambio originales y viables, sobre la convergencia de intereses de los actores sociales. De forma que, los proyectos de diseño industrial que se conciben desde su origen sobre este principio, muestran actualmente mejores posibilidades de concretarse como nuevos productos o servicios en el mercado.

En este sentido se puede decir que la gestión de diseño es la actividad que se practica a través de un proceso, tanto al interior como al exterior de la organización, cuyas funciones básicas son, por un lado, la conducción integral de los procesos y de los actores que posibilitan las acciones de innovación y creación de valor con diseño y, por el otro, la administración de recursos que hace posible la concreción de actividades operativas del grupo de diseño con los demás departamentos de la empresa. Es decir, es una acción de vinculación, en ambos sentidos, entre el diseño industrial y 
su medio, para posibilitar iniciativas de cambio de productos y servicios en la empresa.

En un entorno empresarial estable, como el que prevaleció hasta la mitad del siglo XX, los mecanismos de racionalización mostraron su efectividad para maximizar la productividad. En ese periodo, la planificación fue un instrumento eficaz para anticipar con alta certeza la mejor trayectoria que se debía tomar para lograr el futuro económico y comercial deseado por la empresa. Sin embargo, en un contexto complejo y de gran dinamismo como el de las últimas décadas en el mundo, el pensamiento estratégico adquiere un rol protagónico en el ámbito de los negocios, porque el enfoque analítico de la planificación se muestra insuficiente ante la incertidumbre generada por el cambio permanente y la competitividad. Mas, la incorporación del pensamiento creativo a nivel directivo en las organizaciones, incluida la empresa, no ha sido fácil, como lo mostró la gran reticencia de las escuelas teóricas del management, que por dos décadas trataron de "reducir el concepto y la práctica de la estrategia al ejercicio de la planificación" (Vázquez, 2000).

Fue hasta mediados de la década de los noventa, ante el fracaso de grandes corporaciones que siguiendo técnicas de planeación estratégica se involucraban en procesos altamente burocráticos y de competencia mutuamente destructivos, que se reconoció el enfoque erróneo asumido. La planificación es una herramienta generada por el pensamiento analítico, mientras que la estrategia se deriva del pensamiento creativo, es decir, en palabras de Henry Mintzberg (1993), la estrategia es sintesis, no análisis. Finalmente, Michael Porter nos aclara que ambas herramientas son esenciales para lograr un desempeño superior de la empresa, pero que funcionan en formas muy distintas. "La estrategia significa ser diferente, es decir, escoger deliberadamente un conjunto distinto de actividades para brindar una mezcla única de valor" (Porter, 1997:35-52). Su valor radica en que conduce a las empresas hacia una ventaja real y sostenible sobre sus competidores, basada en un tipo de diferenciación, que trasciende a la que se logra de manera temporal por la eficacia operativa. La planificación, por su parte, sistematiza las actividades requeridas para implementar la estrategia.

Las exigencias actuales del mercado han hecho del diseño un aspecto importante para los negocios; su contribución a la industria y al comercio, 
reconocida plenamente como resultado de estudios económicos que vinculan inversión en diseño con rentabilidad, radica en que es un factor de la innovación y una parte decisiva de la imagen que la empresa proyecta en su entorno, lo que repercute en su competitividad. En este sentido, se reconoce que el conocimiento en gestión resulta definitivo para que los diseñadores industriales competentes en su oficio y críticos de su entorno, se asuman como agentes de transformación de la realidad de las empresas y mejor aún, de la realidad económica y social de los países que apuntan al desarrollo. De otra forma, se diluye el alcance del diseño al convertirse en un mero instrumento de los intereses del mercado.

En la empresa organizada bajo el modelo tradicional mecanicista con disposición de una estructura organizacional suficiente, se entiende a la gestión del diseño como una práctica gerencial a dos niveles; por un lado, la llamada gestión estratégica, que contempla las acciones relativas a la conducción integral de los procesos y actores que apuntan hacia la innovación y generación de valor a través del diseño (objetivo presente en la misión de una empresa con prioridad en el diseño); por el otro, la gestión que se realiza concretamente hacia la parte operativa del proceso de diseño, que hace posible el vínculo fluido y creativo del equipo de trabajo de diseño, con las demás áreas de la empresa. En este contexto operativo, los niveles de actuación del gestor relativos al vínculo plan-programa-proyecto definen, respectivamente, la gestión de políticas y estrategias de diseño a nivel directivo, la gestión de programas de diseño a nivel gerencial y la gestión de proyectos de diseño a nivel de área.

En la práctica, lograr la incorporación del diseño como una prioridad de la empresa es un proceso complejo - ante la baja cultura de desarrollo que en ocasiones caracteriza incluso al propio empresario-, lo que exige la capacidad para sensibilizar a los directivos del valor del diseño (con estudios económicos y ejemplos de caso), e instaurar métodos de gestión asimilables por las demás funciones críticas de la empresa (mercadotecnia, la I+D, ingeniería y finanzas). Al desatender estos factores, las iniciativas de cambio (como el diseño), enfrentarán inercias en contra en todos los niveles de la empresa.

En la formación del gestor de diseño se apunta, entre otros, hacia una combinación de los siguientes rasgos: visión estratégica de futuro, visión interdisciplinaria, capacidad de reacción ante contingencias y habilidades 
interpersonales y grupales y habilidades administrativas. Si bien no todos los diseñadores requieren en su ejercicio de la gestión o gustan de ser gestores, siempre se requerirá de alguien especializado en esta función para concretar las iniciativas a nivel profesional. El reto, entonces, del gestor en diseño es hacer coincidir los fines de todos los actores clave en una iniciativa de diseño. Quizá más claro sería decir que el reto en realidad consiste en tener la habilidad para hacer converger en una iniciativa común, los distintos intereses de los actores del diseño.

Ante la tendencia mundial de las empresas de vanguardia por asumir modelos que permiten una mayor flexibilidad a través de la organización sistémica, se plantean nuevos retos: "Las organizaciones innovadoras y dinámicas requieren que sus miembros desarrollen competencias para gestionar los procesos en que ellos están involucrados. La descentralización de las responsabilidades en las organizaciones, trae aparejadas actividades de gestión en los diversos niveles de mando de las mismas" (Perrone y Propper, 2007:208).

En los países más desarrollados con altos estándares de vida en su población - los países escandinavos, Canadá, Alemania, Francia, países bajos, Australia y Singapur-, la gestión se entiende como un concepto de la práctica organizacional, cuyos alcances trascienden los propósitos de la empresa. De la misma manera, la función del diseño contempla alcances más amplios, orientados a la transformación del entorno social y económico, que van más allá del negocio. Un aspecto fundamental en esa construcción fue que en la práctica política, económica y social de aquellas sociedades, prevalecen históricamente altos estándares éticos, en contraste a lo que ha ocurrido en la práctica latinoamericana (Kliksberg, 2009). Por esto, el factor cultural local, además del problema ético, obliga a una construcción de argumentos propios para la gestión del diseño, válidos en nuestro contexto. Por ejemplo, en las economías desarrolladas es un hecho que el diseño industrial ha adquirido actualmente un rol estratégico para los negocios porque incrementa la competitividad de los productos y, por tanto, su acceso a los mercados globales. Pero este argumento global, en lo local, es parcialmente cierto, porque en la relación causa-efecto que liga la competitividad como consecuencia del factor diseño, se dan por hecho las condiciones suficientes para que esto ocurra (las de una economía desarrollada), como por ejemplo, 
en el sector manufactura productos de alto contenido tecnológico, dirigidos a mercados globales con altos estándares (poder adquisitivo y nivel cultural). De la misma forma, argumentar bajo la relación simple de causa-efecto que la innovación es consecuencia del factor diseño, es parcialmente cierta en nuestro contexto, ya que las innovaciones desarrolladas por la empresa del primer mundo se derivan de un engranaje organizacional y de negocios, altamente especializado, soportado por grandes capitales que permite sintetizar la I+D propia, el diseño total y las estrategias de comercialización globales; es decir, en nuestro contexto, el diseño es condición necesaria de la competitividad, más no es una condición suficiente. Como también es cierto que el diseño es condición necesaria para la innovación, más no es una condición suficiente. $Y$, justamente, el posibilitar la existencia de los demás factores requeridos para concretar el diseño en aquellos términos es, en general, el principal reto del gestor de diseño en nuestro país

Es importante advertir tales supuestos, para contrarrestar la tendencia que se observa en las aulas de lo que podríamos llamar una "cultura de slogans", es decir, una tendencia a reducir conceptos complejos y a argumentar relaciones multi-causales para sustentar al diseño (como por ejemplo las relaciones ya descritas, pero también la relación funcional del diseño con la calidad de vida), sobre frasecillas simples, ingeniosas, pero huecas, que en general reflejan un fenómeno social descrito con profundidad por el sociólogo estadounidense George Ritzer (2008), en su libro La McDonalización de la Sociedad.

En México, como en la gran mayoría de los países occidentales, casi el 99\% de la empresa es pequeña y mediana (PyME). La diferencia primordial con el mundo desarrollado radica en los altos contrastes que se observan en nuestro país y, en general en Latinoamérica, en tomo al nivel de desarrollo que muestran estas empresas. Sólo un bajísimo porcentaje de ellas son empresas tecnificadas y con una estructura organizacional especializada, que comercializan productos con calidad de exportación (De Rivero, 2001).

En respuesta a esta situación en Latinoamérica actualmente hay un gran dinamismo en torno a la formación de organismos de vinculación y redes científicas y tecnológicas, cuyos programas integran a los actores regionales en pro de incorporar el conocimiento a la PyME y al sector comunitario local. Una parte de los proyectos sustentables de desarrollo regional que se 
han concebido, abren importantes oportunidades al diseñador industrial porque apuntan a la exportación de sistemas de productos para el mercado global, donde el factor diferenciador primordial es lograr la expresión cultural local con originalidad. Pero quizá la oportunidad mayor para el diseñador está en la posibilidad de que sea él quien conciba y dirija este tipo de proyectos, que fincan su valor en la originalidad de la idea-negocio y en la capacidad para generar productos diferenciados de alta calidad estética y cultural. Por supuesto, ésta última opción requiere que el diseñador domine las herramientas de gestión.

Francisco Javier Gutiérrez Ruiz 


\section{Bibliografía}

Alvares De Mon Santiago (2001), El mito del líder. Profesionales, ciudadanos, personas: la sociedad alternativa", España: Prentice Hall.

BOISVERT, Jacques (2004), La formación del pensamiento crítico: teoria y práctica, México: Fondo de Cultura Económica.

САВот, Juan Enríquez (2001), El reto de México: tecnología y fronteras en el siglo XXI, Editorial Planeta 7.

Calva José Luis (Coordinador) (2007), Desarrollo económico: Estrategias exitosas", México: UNAMPorrúa.

De Rivero, Oswaldo (2001), El mito del desarrollo. Los paises inviables del siglo XXI, México: Fondo de Cultura Económica.

GARCía, Néstor (2009), "Consumidores y ciudadanos Conflictos multiculturales de la globalización", México: Debolsillo.

KLIKSBERG, Bernardo (2009), Más ética, más desarrollo, Buenos Aires, Argentina: Grupo Editorial SRL.

KofmAN, Fredy (2003), Metamanagement. La nueva con-ciencia de los negocios, México: Ediciones Garnica.

López, Alfredo (2005), El modelo en la ciencia y la cultura, México: UNAM-Siglo XXI Editores.

MARZANo, Michela (2011), Programados para triunfar. Nuevo capitalismo, gestión empresarial y vida privada, España: Tusquets Editores.

Mena, Marco (2011), Gestión de la crisis, México: Siglo XXI Editores.
Micheli, Jordy (2008), Conocimiento e innovación: retos de la gestión empresarial, México: UAM, UNAM, Plaza y Valdes Editores.

Mintzberg, Henry (1993), The Rise and Fall of Strategic Planning, New York: The Free Prees.

PerRone Graciela y Propper Flavio (2007), Diccionario de educación, p. 208.

Polo, Leonardo-Llano, Carlos (1997), Antropología de la acción directiva, España: AEDOS Unión Editorial.

PORTER, Michael (1997), “¿Qué es estrategia?”, en Revista INCAE, Vol X, No 1, pp. 35-52.

Ritzer, George (1996), La McDonalización de la sociedad, Barcelona: Ariel Sociedad Económica.

RADDER, Hanz (2006), The world observed / the world conceived, University of Pittsburgh Press.

RODRÍGUez, Darío (2001), Gestión organizacional. Elementos para su estudio, México: Plaza y Valdés Editores.

RODRIGUez, Luis (2006), Diseño: estrategia y táctica, México: Siglo XXI Editores.

RoszaK, Theodor (2005), El culto a la información. Un tratado sobre alta tecnologia, inteligencia artificial y el verdadero arte de pensar, España: Editorial Gedisa.

SARTORI, Govanni (2005), Homo videns. La sociedad teledirigida, México, Punto de Lectura.

TEDESCO, Juan (2007), Educar en sociedad conocimiento, México: Fondo Cultura Económica.

VÁZOUUEZ, Alfonso (2000), La imaginación estratégica, México: Ediciones Garnica. 


\section{Actores sociales y diseño industrial}

\section{Definición Diccionario RAE (DENOtACIÓN)}

Actor $^{1}$, ra. (Del lat. actor, -ōris). 1. m. y f. Participante en una acción o suceso.

Actuar. (Del lat. mediev. actuāre). 1. tr. Poner en acción. U. t. c. prnl. 4. intr. Dicho de una persona o de una cosa: Ejercer actos propios de su naturaleza. 5. intr. Ejercer funciones propias de su cargo u oficio. 6. intr. Dicho de una cosa: Producir efecto sobre algo o alguien. Esa medicina actúa como somnifero. 7. intr. Obrar, realizar actos libres y conscientes. 8. intr. Practicar los ejercicios de una oposición.

\section{DesarRollo o CONSTRUCCIÓN DEL CONCEPTO}

Las iniciativas de diseño de nuevos productos normalmente surgen en la empresa, al detectar necesidades mal cubiertas en el mercado, o al reconocer oportunidades internas para cubrirlas con ventaja si se dispone de mejores capacidades que el competidor. En su concreción como nuevos productos de impacto social, los actores sociales juegan un rol estratégico con frecuencia desconocido por los estudiantes de diseño industrial..

A partir de la definición que la Real Academia Española hace del concepto actor, el interés se centra sobre aquellos participantes de un entorno social concreto que al ejercer actos propios de su naturaleza, producen un efecto específico en la actividad del diseño en cualquiera de sus manifestaciones o también, en sentido inverso, en aquellos que se ven afectados por estas manifestaciones. El efecto no siempre es de impulso; un actor también influye cuando inhibe o bloquea un proceso de cambio, como reacción a la afectación de sus intereses. Bajo esta lógica, se puede inferir que los actores de diseño industrial (actores sociales que interactúan por iniciativa propia con el hacer del diseño industrial), son aquellos grupos, organizaciones e instituciones que representan grupos de intereses (políticos, económicos y de poder), presentes en el "juego de hacer diseño" en un entorno social particular. Por lo que, participan e interactúan en este entorno o "campo de juego", buscando beneficios, bajo algunas reglas escritas, pero otras no escritas.

Al incorporar el concepto de actor al proceso de diseño industrial emerge una complejidad subyacente alrededor de las iniciativas de cambio, especialmente aquellas de alto impacto social (que inciden en intereses múltiples, por ejemplo, introducir un sistema de parabuses y mobiliario urbano en cierta localidad) o, de aquellas que por su magnitud sólo son posibles bajo la articulación de los actores sociales de la región. Observar el entorno social y empresarial como un juego de intereses en conflicto y fuerzas de poder, permite al diseñador ampliar su enfoque hacia la búsqueda de convergencias, integración de recursos y distribución de beneficios, en el hacer del diseño en un ambiente social o empresarial concreto.

Por "hacer del diseño" se entiende aquí a toda manifestación de diseño relativa a, la formación de diseñadores, el ejercicio profesional como diseñador, la investigación en diseño y la 
incidencia social y cultural que generen estas tres actividades fundamentales. Tal diversidad contempla tareas que van desde una propuesta de proyecto profesional concreta, el lanzamiento de un producto diseñado al mercado, la disputa sobre la propiedad de una idea entre dos empresas, una nueva oferta de diseñadores formados bajo un modelo educativo particular, la difusión de una exposición de diseño en la localidad o un proyecto de envergadura que afectará a la localidad. El interés que impera en torno a una acción de diseño define el tipo de relación que se entabla entre actores, pudiendo ser: de beneficio, afectación, confrontación, alianza, apoyo, simulación o arbitraje. Definidas las posturas, los actores adquieren connotaciones como: socios, aliados, promotores, observadores, detractores $\mathrm{u}$ opositores y clientes, de un proyecto.

Una práctica común al impulsar iniciativas de impacto social - por ejemplo el diseño de los sistemas de transporte urbano- es el cabildeo, negociación informal, anticipada y por separado con los actores decisivos de la región, para sondear reacciones, opiniones, y negociar opciones de solución al conflicto y, finalmente, "ganar con maña voluntades" (Diccionario de la Real Academia Española), que serán decisivas en la negociación formal. En teoría, el cabildeo y la negociación se desarrollan en el marco de la diplomacia, pero particularmente en nuestra cultura, subyace en ellas el ejercicio del poder, como lo muestran estudios sobre prácticas culturales de los mexicanos, realizados por autores extranjeros como Alan Riding con su libro "Vecinos distantes. Un retrato de los mexicanos".
Si el conflicto persiste, surge la confrontación y los actores ejercerán su derecho a defender sus intereses bajo el marco normativo correspondiente (financiero, productivo, comercial, jurídico, etc.), a través de mecanismos de: negociación, mediación, arbitraje o litigio.

Un proyecto profesional de diseño, generará un grupo de actores, conformado normalmente por los inversionistas, directivos, competidores, proveedores y comercializadores. Pero, en proyectos de mayor envergadura se debe prever la eventual intervención de otros actores que pueden resultar decisivos, como son: Instituto Mexicano de la Propiedad Intelectual (IMPI), Colegio de Diseñadores Industriales y Gráficos de México (CODIGRAM), Centro Promotor de Diseño México (CPD-México), así como organismos públicos y privados (locales, estatales o nacionales) de: financiamiento (Nafin), fomento tecnológico y productivo (Secretaría de Economía), cámaras empresariales (Canacintra, Concamin) y embajadas de otros países en México.

Las agencias gubernamentales -agencias públicas con funciones especializadas de carácter técnico, productivo, ambiental, de propiedad intelectual, etc.- con frecuencia participan como árbitros para dirimir conflictos derivados del "hacer del diseño". Entre sus funciones destacan: definir normatividad sobre productos, certificar su cumplimiento, definir y ejecutar sanciones, generar nuevas normas para productos, así como hacer peritajes sobre aspectos especializados necesarios para dirimir las controversias, por ejemplo, sobre la propiedad intelectual de una idea. 


\section{USOS O ACEPCIONES (ACLARACIONES)}

La amplitud del enfoque con se aborda un problema de diseño, determina el tipo y cantidad de actores a participar en su solución, lo que puede contemplar, únicamente los actores del proyecto, los actores del problema o hasta incluir al total de los actores sociales de una localidad para concretar la iniciativa de diseño.

\section{SINÓNIMOS}

Grupos de interés, actores sociales, "jugadores", grupos de poder, agentes del cambio.

\section{ANTÓNIMOS}

Sectores sociales.

\section{EJEMPLOS}

1. Un ejemplo ilustrativo de la interacción entre actores en un entorno particular, lo es la eventual promoción repentina que hace un fabricante de sus productos (reducción significativa y temporal del precio), como reacción ante el lanzamiento de un nuevo producto competidor, con el propósito de contrarrestar la probable baja en sus ventas.

2. La fabricación e instalación de parabuses y mobiliario urbano en una ciudad, es un proyecto que necesariamente involucra a los actores de la región en un sistema de acuerdos, compromisos y beneficios que hacen posible la concreción del proyecto Véase: entorno empresarial.

\section{Bibliografía}

ASTIÉ-BURGOS, Walter (2011), Lobby y democracia: 10 positivo y negativo del cabildeo, México: Siglo XX! Editores.

ARROYO, Juan (2002), Cultura empresarial.

Formación básica de empresarios para una mayor productividad, México: UNAM-Secretaría de Economía

BouRdieu, Pierre (2002), Campo de poder, campo intelectual. Itinerario de un concepto, Editorial Montresso.

DELOITTE \& Touche (2003), Administración integral de riesgos de negocio, México: Instituto Mexicano de Ejecutivos de Finanzas A.C.

GutiéRrez, Francisco (2005). Ejercicio Profesional del Diseño Industrial 2. Un Acercamiento a las Especialidades más Dinámicas en México, México: UAM AzC. (2003), Ejercicio Profesional del Diseño Industrial. Un acercamiento a las especialidades más dinámicas en México, México: UAM Azc. Lomelí, Luz (2011), "Modernidad y sujetos sociales", en Alain Touraine, en Revista Debate, ITESO.

MARZANo, Michela (2011), Programados para triunfar. Nuevo capitalismo, gestión empresarial y vida privada, España: Tusquets Editores.

Moscovici, Serge (1979), El psicoanálisis, su imagen y su público. Buenos Aires: Editorial Huemul S. A. OIT (1988), La Consultoria de Empresas, Ginebra: Organización Internacional del Trabajo. RODRÍGUeZ, Luis (2006), Diseño: estrategia y técnicas, México: Siglo XXI, Editores. 


\section{Capacidad de la empresa para innovar}

\section{Definición Diccionario RAE (DENOtACIÓN)}

Capacidad (Del lat. capačrtas, -ātis). 2. f. Aptitud, talento, cualidad que dispone a alguien para el buen ejercicio de algo. 5. f. de sus. Oportunidad, lugar o medio para ejecutar algo.

Innovar (Del lat. innovāre). tr. Mudar o alterar algo, introduciendo novedades

Innovación (Del lat. innovať̌o, -ōnis). 1. f. Acción y efecto de innovar. 2.f. Creación o modificación de un producto, y su introducción en un mercado.

\section{DESARROLLO O CONSTRUCCIÓN DEL CONCEPTO}

El ambiente de alta competitividad impuesto por el mercado global desde las últimas décadas del siglo XX, ha repercutido de formas muy diversas en los sectores industriales de manufactura de nuestro país. Un factor que marcó diferencia en este impacto fue la solidez económica, tecnológica y organizacional de cada sector y en particular de cada empresa. En relación con la competitividad del producto, algunas empresas lograron mejorar sus productos, otras tomaron opciones alternas para mantenerse en el mercado, como importar el producto que llegaba del exterior, y las más, desaparecieron ante la imposibilidad de adaptación. A partir de este fenómeno se ha venido experimentando una serie de transformaciones en la dinámica de las especialidades profesionales del diseño industrial en el país como resultado, entre otros factores, de la capacidad real para innovar que tienen los sectores productivos y cada empresa en particular.
Si la opción de una empresa ante el embate globalizador es desarrollar mejores productos, conviene iniciar el proceso con la evaluación de sus capacidades para innovar, con frecuencia desconocidas o confusas para sus propios directivos. Esta precaución técnica es deseable, porque las actividades de desarrollo e innovación (aquellas que buscan cambiar lo convencional por lo nuevo que incorpora valor) responden a una lógica radicalmente distinta de la requerida para racionalizar la manufactura de los productos de línea (optimizar lo convencional); es decir, una empresa que ha sido eficiente en la manufactura cotidiana de sus productos, puede resultar muy ineficiente tratando de desarrollar nuevos productos.

De la definición que hace la Real Academia Española del concepto innovación, se infiere que esta aptitud para crear o modificar productos con novedades que impacten con éxito el mercado implica, de inicio, un conocimiento real de la naturaleza del proceso de desarrollo de productos, cuya particularidad primordial radica en la dificultad de hacer supuestos iniciales que resulten correctos a futuro, cuando el entorno es convulso. Yoguel y Boscherini (1999) definen la capacidad para innovar de la empresa como "la potencialidad de idear, planear y realizar innovaciones a partir del uso de los conocimientos tecnológicos y organizativos, tanto formales como informales, presentes en la firma y/o contratados externamente en el mercado" (Bianchi y Miller, 1999:267). Es decir, la capacidad para innovar de una empresa se puede expresar como capacidad para convertir 
conocimiento propio, en valor agregado en sus productos.

En el caso de productos manufacturados de mediana y alta complejidad - productos cuya estructura se conforma de una diversidad de sistemas diferentes, cuya manufactura requiere de una inversión importante en herramental一, el proceso de innovación exige recursos como: conocimiento tecnológico propio, un Know how para conducir con eficacia el proceso, recursos económicos y tecnológicos para sustentarlo, una estructura organizacional especializada y una cultura organizacional experimentada sobre procesos que sistematizan el cambio, especialmente en lo relativo a la generación, maduración, concreción y protección de una idea capaz de generar la rentabilidad esperada.

Esta potencialidad de idear, planear y realizar innovaciones depende, en parte, del entorno transaccional y contextual de la empresa (véase entorno empresarial), como apunta muy bien Michael Porter: "La capacidad de cualquier empresa para innovar tiene mucho que ver con el entorno al que está expuesta... la innovación tiene éxito porque el entorno nacional la apoya e incluso la fuerza... el entorno adecuado no solamente da forma a las propias percepciones y prioridades del líder, sino que produce una catálisis que permite al líder superar la inercia y crear un cambio en la organización" (1991:724)

Apenas hace unas décadas, en las que imperaban las economías de escala en la producción, la gran empresa dominaba los procesos de innovación del producto al disponer de recursos para concretarlos. El alto rendimiento generado por sus casos de éxito se invertía en nuevos procesos de "Investigación y Desarrollo" (I+D) —acciones que realizan para convertir dinero en conocimiento- y absorbía los muy frecuentes fracasos. Bajo las nuevas exigencias del mercado que impactan al producto, como la reducción notable de su ciclo de vida, la tendencia a aumentar su contenido tecnológico, su movilidad entre regiones y la necesidad de "personalizarlos" para satisfacer a un consumidor exigente con preferencias cambiantes, se alteró notablemente el proceso convencional para innovar productos y se redujo el tiempo requerido para hacerlo.

Ante las nuevas exigencias económicas globales sumadas a la necesidad de detonar procesos de desarrollo regional, emerge el rol estratégico de la Pequeña y Mediana Empresa (PyMEs) por su alta flexibilidad al cambio, su contribución al empleo y su capacidad de "arrastre" a los demás sectores económicos de la región. En este contexto, algunos modelos de innovación plantean nuevas formas de concebirla a partir de la ampliación de las capacidades para innovar de este sector empresarial, focalizándolas hacia proyectos sustentables que detonen el desarrollo regional, posibles bajo la articulación de los actores sociales. La tendencia a involucrar a los actores sociales, públicos, privados y de la sociedad civil (institutos de I+D, universidades, agencias financiadoras, agencias promotoras de comercio y organizaciones no gubernamentales, ONGs), en la concreción de estas iniciativas, amplía notablemente los recursos disponibles (financiamiento, tecnología y capital intelectual), posibles de captarse 
desde las agencias nacionales de gobierno o de las redes internacionales de colaboración.

En nuestro país los procesos de innovación en las PyMES y en los esquemas de producción comunitaria se impulsan desde los diversos gobiernos a través de programas, como el Programa Nacional de Innovación (2011) de la Secretaría de Economía del gobierno federal. Sin embargo, el modelo del fomento del gobierno federal, por ejemplo, considera a la innovación más como un problema de racionalización tecnológica y productiva orientada hacia las exigencias comerciales del mercado, que como un proceso de impulso real de las capacidades internas de las PyMEs, para potenciar, desencadenar y fortalecer los procesos del desarrollo local.

\section{USOS O ACEPCIONES (ACLARACIONES)}

\section{SINÓNIMOS}

Capacidad de inventiva, capacidad de innovación.

\section{ANTÓNIMOS}

Capacidad productiva, capacidad tecnológica.

\section{EJEMPLOS}

Un caso exitoso del modelo lo constituye el Programa "Pueblos mágicos" impulsado por la Secretaría de Turismo desde el año 2001, cuya finalidad ha sido el impulsar, no sólo económica, sino también social y culturalmente a diversas regiones del país con atractivos turísticos singulares. Las acciones de cooperación nacional e internacional llevadas a cabo, han impactado notablemente el desarrollo de diversas localidades, a través de un modelo de desarrollo turístico sustentable.

Véase: Innovación, desarrollo sustentable.

\section{Bibliografía}

De Bono, Edward (2002), El pensamiento creativo. El poder del pensamiento lateral para la creación de nuevas ideas, México: Paidós.

GARDNER, Howard (2004), Mentes flexibles", México: Paidós.

JERRY Palmer y Mo Dodson (2006), Design and aesthetics, New York: Routledge.

Martínez, José (2002), Marketing de servicios profesionales. Para la pequeña y mediana empresa, España: Prentice Hall,

OCDE-Eurostat (2000), “Manual OSLO", en La medición de las actividades cientificas y tecnológicas. Directrices para recabar e interpretar datos de la innovación tecnológica, México: IPN.

PHillips, Peter (2008), Cómo crear el brief de diseño perfecto, México: C.E.C.C.

PoncE, Adelaida y Sánchez, Gutiérrez (2010), Cooperación internacional para el desarrollo local. Aspectos estructurales, experiencias, oportunidades y limitaciones, México: UAM Azc., Instituto Mora.

PORTER, Michael (1991), La ventaja competitiva de las naciones, Argentina: Javier Vergara Editor,

SCHRAGE, Michael (2001), Juego serio: cómo las mejores compañias usan la simulación para innovar, México: Oxford, University Press.

YoGUEL, Gabriel; Boscherini, Fabio (1999), "El ambiente y el desarrollo de los procesos innovativos: un modelo interpretativo de las 
actividades incrementales desarrolladas por las PyMES argentinas", en Innovación y territorio. Politicas para las pequeñas y medianas empresas, México: Editorial Jus.

\section{Cultura de desarrollo}

\section{Definición Diccionario RAE (DENOtACIón)} Cultura. (Del lat. cultüra). 1. f. Cultivo. 2. f. Conjunto de conocimientos que permite a alguien desarrollar su juicio crítico.

Desarrollo. 1. m. Acción y efecto de desarrollar o desarrollarse. 3. m. Econ. Evolución progresiva de una economía hacia mejores niveles de vida.

\section{DESARROLLO O CONSTRUCCIÓN DEL CONCEPTO}

Al introducir el factor cultural al estudio y la práctica de la gestión de diseño, se amplía notablemente la perspectiva de análisis sobre la factibilidad de sus iniciativas en nuestro contexto, que debiendo decidirse sobre la racionalidad de los análisis técnicos, ${ }^{1}$ con frecuencia se dirimen por la subjetividad. Dos causas destacan en esta situación: el juego de intereses entre actores (véase actores de diseño) y el "sentir" que prevalece en quienes toman las decisiones sobre los procesos de cambio hacia la mejora e innovación, es decir, "el cambio hacia lo nuevo", particularmente en la cultura de este país, se decide en una esfera de valores e intereses subjetivos que con frecuencia trascienden su valoración técnica; muestras cotidianas de ello se observan en la vida pública de México en cualquier diario nacional.
Observar el proceso del desarrollo bajo el lente cultural tiene el propósito de adecuar el modelo a la esfera de valores y creencias generales de un entorno particular, relativos al sentir, asumir y enfrentar los procesos de cambio e innovación. A lo largo de la historia como país, se han arraigado patrones de pensamiento y comportamiento (valores, costumbres, creencias y hábitos), a pesar de la diversidad y multiculturalidad del país, que actualmente inhiben la voluntad del mexicano para perfeccionar la cultura material como medio de progreso. Estos patrones tienen sus raíces en fenómenos complejos del devenir histórico nacional, de carácter social, cultural, político y educativo. La apatía y reticencia actual hacia el cambio, manifiesta en formas y estratos diversos, nos resulta ajena a los diseñadores y, en general, a los creadores, porque somos formados dentro de una esfera de valores del cambio; de suerte que sus procesos nos resultan familiares. Sin embargo, para los formados en otra esfera de valores (por ejemplo, los de la certidumbre), los procesos de cambio hacia lo nuevo se perciben a priori, como riesgosos.

En la psicología se sabe que un mecanismo natural del pensamiento es su predisposición por lo conocido y su aversión hacia lo nuevo, como recurso de protección ante el error (Wayne, 2008: Cap. V). Que bajo un medio fértil que cultive los valores y principios del desarrollo se

1. En los negocios, priva la certidumbre de la inversión evaluada a través de estudios de rentabilidad, de riesgos y de factibilidad tecnologicaproductiva. 
adquieren pautas y confianza para percibir y enfrentar el cambio como una oportunidad de progreso. Ante el desconocimiento del fenómeno se cree que cambiar estas pautas requiere sólo de infundir nuevos hábitos (por ejemplo, incentivar al trabajador con buenas prácticas) o, de impulsar las iniciativas que surjan espontáneamente de la población. ${ }^{2}$ Sin embargo, estudios que escudriñan las causas culturales del fracaso, así como aquellos que desentrañan nuestras particulares prácticas culturales (A. Von Humbodlt, Samuel Huntington, Alan Riding y Octavio Paz), muestran que cambiar el sentir del mexicano sobre la necesidad, confianza y deseo de mejorar y emprender con honestidad, es un proceso educativo integral de largo plazo paralelo a la permanente construcción de un entorno social fértil hacia el cambio. Al respecto, de poco sirven los mensajes correctivos a la población, cuando se observan pautas altamente nocivas en el emisor.

La advertencia del politólogo estadounidense Samuel Huntington (1997) en su libro "El choque de civilizaciones", versa precisamente sobre las graves consecuencias que observa para la cultura anglosajona, si los inmigrantes mexicanos "insisten" en mantener sus arraigadas prácticas culturales.

En el ámbito profesional, la percepción de los directivos que toman las decisiones para mejorar productos con diseño industrial, por lo

\footnotetext{
2. Institucionalizando un sin fin de programas de fomento, como: Programa Nacional de Innovación; Programa Nacional de Competitividad; Proyecto "Iniciativa México", etc.
}

general está impregnada de valoraciones negativas hacia el cambio; no sólo porque su naturaleza confronta el anhelo de certidumbre en los negocios, sino además, porque el particular enfoque del diseño industrial se percibe como una sofisticación innecesaria que puede ser resulta con opciones más sencillas, por ejemplo, copiando lo que ha resultado bien en otro contexto. De esta forma, algunas pautas inhibidoras del desarrollo, presentes en políticos, funcionarios, inversionistas, empresarios, directivos, administradores y gerentes, se manifiestan en expresiones típicas como: "las soluciones conocidas son mejores porque no presentan riesgos"; "las nuevas ideas verdaderamente valiosas se generan en el extranjero"; "para que complicarnos si se puede copiar un producto extranjero sin problema" y otras más. Aunque estas apreciaciones pudieran tener parte de verdad, con frecuencia se sustentan sobre el temor al cambio o sobre la costumbre muy mexicana de los "listos" (lograr "lo mismo", pero por el camino fácil).

Un antídoto eficaz del diseñador ante este problema es, por un lado, mostrar altos estándares profesionales en diseño relacionados a la toma de decisiones en proyectos de riesgo y, por el otro, comprender cabalmente la naturaleza del factor subjetivo en la toma de decisiones hacia la mejora e innovación. Russel Ackoff nos advierte claramente que el subdesarrollo es más una condición mental que un estado de carencia real: "no es tanto cuestión de lo que se tiene sino de lo que se hace con lo que se tiene". El desarrollo es el deseo y habilidad de utilizar lo disponible para mejorar continuamente la 
GESTIÓN Y DISEÑO INDUSTRIAL 191 CULTURA...

calidad de vida, habilidad que no pueden dar a otros, los que ya la tienen. La debe desarrollar cada quien para sí mismo" (Ackoff, 1974:287).

\section{SINÓNIMOS}

Baja cultura de desarrollo, inmovilismo ante el cambio, prácticas culturales que inhiben el desarrollo.

\section{ANTÓNIMOS}

Cultura emprendedora, necesidad de logro, emprendedurismo.

\section{EJEMPLOS}

La negativa del empresario mexicano a invertir en desarrollo de nuevos productos por temor al fracaso, aun teniendo condiciones convenientes y necesidad de hacerlo, se transforma repentinamente cuando viaja al extranjero y regresa asombrado con algún producto innovador, con el propósito de manufacturarlo en su empresa, lo que demuestra que, ante una idea nueva ya resuelta (el nuevo producto), sus creencias y temores se desvanecen rápidamente.

\section{Bibliografía}

AcкоғF, Russell (1997), Rediseñado el futuro, México: Editorial Limusa; Noriega Editores.

BARTRA, Roger (2002), Anatomía del mexicano, México: Plaza y Janés Editores.

CASSIRER, Ernst (1972), Las ciencias de la cultura, México: Fondo de Cultura Económica.

CASTAÑEDA, Jorge (2011), Mañana o pasado. El misterio de los mexicanos, México: Edit. Aguilar.
CORTINA, José María (2006), Identidad, identificación, imagen, México: Fondo Cultura Económica.

Díaz-Guerrero, Rogelio (2008), Psicología del mexicano. Descubrimiento de la etnopsicología. México: Editorial Trillas.

DREVILLON, Jean (1978), Psicología de los grupos humanos, Argentina: Ediciones Nueva Visión.

Enríuezz, Juan (2000), El reto de México: tecnología $y$ fronteras en el siglo XXI, México: Editorial Planeta.

Huntington, Samuel (1997), El choque de las civilizaciones y la reconfiguración del orden mundial, Barcelona: Paidós.

Kantis, Hugo (Ed.) (2004), Desarrollo emprendedor. América Latina y la experiencia internacional, Colombia: BID-FUNDES Internacional.

MARINA, José (2006), La inteligencia fracasada. Teoría y práctica de la estupidez, Barcelona: Anagrama.

R.C. Lewontin, S. Rose y L.J. Kamin (2009), No está en los genes. Racismo, genética e ideologia, Barcelona, España: Crítica.

RaPAIlle, Clotaire (2007), El código cultural, México: Grupo Editorial Norma.

RIDING, Alan (1985), Vecinos distantes. Un retrato de los mexicanos, México: Editorial Planeta.

THOMPSON, John (2002), Ideología y cultura moderna. Teoría crítica social en la era de la comunicación de masas, México: UAM Xochimilco.

VAlverdE, Karla; Salas-Porras, Alejandra (2005), El desarrollo. Diversas perspectivas, México: Editorial Gernika.

WAYNe W. Dyer (2008), Tus zonas erróneas, Cap. V., España: Editorial Debolsillo. 


\section{Diferenciación de productos (o la mercadotecnia, el diseño y las estrategias de competitividad)}

\section{Definición Diccionario RaE (Denotación)}

Diferenciar. Hacer distinción entre personas o cosas: no diferencia bien los sonidos. Diferir, distinguirse una persona o cosa de otra: nos diferenciamos en muchas cosas.

\section{DESARROLLO O CONSTRUCCIÓN DEL CONCEPTO}

En un contexto atemporal, el diseño es esencialmente la aplicación de la creatividad humana para un determinado propósito. En diversos momentos, el diseño ha impactado en el desarrollo de la humanidad, en el plano tecnológico la revolución industrial es una de ellas, en el académico la Bauhaus ha sido otra; esta efímera pero importante escuela alemana motivó y educó a su alumnado hacia la creación de una obra para ser producida en serie y tener una utilidad social, tesis valida y vigente hasta nuestros días. En la actualidad el diseño gráfico, industrial o textil, se imparten en muchos de los casos en escuelas de arte o ingeniería, sin embargo, contrario a lo que se piensa en las escuelas de arte, la mercadotecnia al igual que el diseño cumple la función de planear y crear productos y servicios que permiten obtener un mayor nivel de vida.

Un error "académico" y profesional es considerar a la mercadotecnia como el arte de vender productos, porque el objetivo de esta disciplina no son las ventas, sino conocer y entender a los clientes lo suficientemente bien para que el producto o servicio generado no únicamente cubra sus necesidades sino que, en lo posible, las exceda, logrando que se venda casi solo. Diversas autoridades de la mercadotecnia, Levit, Kotler, sobre todo, McCarthy, han señalado que en su disciplina existen cuatro elementos esenciales que mezclados pueden optimizar las actividades de negocios de las empresas: las llamadas 4 Ps de la mercadotecnia; ¿pero cuáles son, en qué consisten y cómo el diseño interactúa con ellas?

La primera se refiere al producto y abarca los bienes tangibles e intangibles que produce $u$ ofrece una empresa, estos últimos denominados servicios; en relación a los tangibles el diseño influye en su costo, calidad, función, apariencia e interacción con el usuario; además determina las características esenciales del producto, mismas que permiten agregar valor para el cliente. En cuanto a los servicios, el diseño genera la información gráfica necesaria para hacer visible lo intangible. Ken Cato, el prestigioso diseñador australiano, va más allá al afirmar que el diseño permite hacer visible la estrategia de la empresa.

El segundo elemento es el precio, y se determina por la suma de los costos directos e indirectos más la ganancia deseada. Aquí el diseñador juega nuevamente un papel importante ya que él puede proponer el material que mejor convenga al proyecto de acuerdo a la política de costos y precios de la empresa, es decir, seleccionar un material con mejor calidad que permita incrementar el valor percibido por el cliente y que, en consecuencia, si así 
lo considera la compañía, aumentar el precio. Asimismo, el diseñador puede sugerir un material o método de manufactura que sea más económico sin detrimento de la calidad, esto último ofrece dos posibilidades: bajar el precio del producto o bien incrementar el margen de ganancia de la empresa.

La tercera "P" se refiere a la plaza, todo producto se comercializa en un determinado lugar que puede variar de región en región. El diseñador deberá estar muy consciente de esto a fin de planear el empaque necesario para el producto; factores como la distribución, el almacenaje y el embalaje deben ser ampliamente considerados. El envase no sólo deberá proteger al producto, adicionalmente podrá informar sobre él y en determinados casos formar una conciencia al cliente sobre su uso. La aplicación de estándares es crucial, sobre todo en los empaques para productos de exportación.

La última "P" y a la que equivocadamente se le considera como la única estrategia de mercadotecnia es la de promoción, muchas de las tareas que se efectúan para la difusión recaen en el proceso de la comunicación, sin embargo, esta labor es interactiva ya que si mercadólogos y diseñadores participan en la generación del concepto del producto, éste será parte de los atributos claves que se expondrán gráficamente, no únicamente en su lanzamiento sino durante el ciclo de vida del mismo.

Como podemos ver, la interacción de las cuatro "P" con el diseño es muy estrecha y se puede dar en diferentes grados en las diversas etapas de la mezcla de mercadotecnia: las actividades de generación de la idea para un nuevo producto, la factibilidad de realizar el mismo, la investigación de mercado, el análisis de: Fortalezas, Oportunidades, Debilidades, Amenzas (FODA) interno, la planeación de éste, el estudio de los competidores y la promoción del producto, entre otros, son labores que deben ser compartidas por ambas disciplinas. El no involucramiento de diseñadores en la toma de decisión de esas y otras actividades ha generado lo que Peter Gorb y Angela Dumas de la Open University en Inglaterra, denominan "diseñadores silenciosos", el término se refiere a aquellos profesionales no diseñadores, principalmente mercadólogos, quienes toman decisiones de diseño que afectan el desarrollo de un proyecto de diseño.

A fin de optimizar las labores de los diseñadores y mercadólogos en la planeación de cualquier tarea de diseño, es necesario la elaboración de un listado de requerimientos, documento que debe contener la parte racional del diseño, más la información del mercado y la información tecnológica, datos que pueden ser recolectados y compartidos por el equipo interdisciplinario involucrado en el desarrollo de un diseño como se apunta líneas antes, la importancia del documento es crítica ya que con base en la información es posible determinar, entre otras características, el costo, precio y atributos del producto.

Para Michael Porter (1986), profesor de la escuela de negocios de la Universidad de Harvard existen tres principales estrategias para la competitividad de una empresa: a) liderazgo en costos b) diferenciación, c) enfoque 
o alta segmentación. Muchas empresas, particularmente las de los paises en vías de desarrollo, fundamentan su competitividad en bajos costos y desafortunadamente México no es la excepción.

Si bien el diseño puede ayudar en cada una de las estrategias propuestas por Porter, la estrategia de diferenciación es fundamental en el diseño ya que si todas las empresas poseen las mismas tecnologías lo único que podrá diferenciar su producto será el diseño.

\section{USOS O ACEPCIONES (ACLARACIONES)}

Diferenciación de productos.

\section{SINÓNIMO}

Singularizar.

\section{ANTÓNIMO}

Igualdad.

\section{EJEMPLOS}

El diseño permite la diferenciación de productos de aquellas empresas que compiten en los mismos sectores.

\section{Bibliografía}

KotLer, Philip (2000), Marketing Management, Estados Unidos: Editorial Prentice Hall. PORTER, Michael E. (1986), Estrategia competitiva, México: Editorial Patria. (1985), Competitive advantage, New York: Free Press.

\section{Entorno empresarial}

Definición Diccionario RaE (DEnotación) Empresa. (Del it. impresa). 2. f. Unidad de organización dedicada a actividades industriales, mercantiles o de prestación de servicios con fines lucrativos.

Entorno. (De en- y torno). m. Ambiente, lo que rodea.

\section{DESARROLLO O CONSTRUCCIÓN DEL CONCEPTO}

En la sociedad contemporánea, las diversas necesidades son cubiertas por todo tipo de empresas que compiten en el mercado para satisfacer necesidades y preferencias cada vez más específicas. Este fenómeno plantea a los diseñadores mexicanos una pregunta importante relativa a la competitividad de los nuevos productos: ¿cómo las características de la región donde opera una empresa influyen en su función principal de manufacturar rentablemente productos competitivos?

El entorno empresarial, conceptualmente, se entiende como aquellos aspectos, condiciones o circunstancias, externos a la empresa, derivados del lugar donde opera, que influyen en su funcionamiento. Este concepto asimilado de los sistemas biológicos (condiciones del medio que rodean y permiten sobrevivir al ser vivo), se torna complejo y dinámico en su sentido organizacional. Para manejarlo, se le ha esquematizado desde diversas disciplinas con perspectivas e intereses particulares a partir de la fragmentación de los factores, actores e interrelaciones que conforman el entorno social; por ejemplo, 
un enfoque económico centra su interés en el comportamiento de los agentes económicos básicos del entorno: familias, empresas, instituciones financieras y el Estado (en su función re guladora); mientras que un enfoque sociológico lo centra en las relaciones funcionales entre los sectores sociales (productivo, financiero, comercial, laboral, empresarial, etc.). La mercadotecnia enfoca su interés en la satisfacción de las necesidades de los consumidores, clasificándolos por estilos de vida y poder adquisitivo.

Una esquematización útil al diseño industrial en su enfoque estratégico, se deriva de la perspectiva del análisis de escenarios propuesta por Emery y Trist (1965), quienes definen dos categorías del entorno empresarial basadas en el grado de influencia que es capaz de ejercer la empresa: "el entorno transaccional es la parte del entorno en el que la organización (empresa en este caso) es un participante importante, influyendo en los resultados en la misma medida que recibe la influencia por ellos. Esto a veces se conoce como el campo de juego, para el que la organización desarrolla la estrategia a fin de convertir el juego para su propia ventaja" (Van Der Heijden, 1998:20). Al entorno transaccional de la empresa pertenecen sus clientes, proveedores, competidores directos, comercializadores, fuerza laboral y características del lugar donde se asienta la empresa. Por otro lado, "El entorno contextual es la parte que tiene importantes repercusiones para la organización, pero en el cual ésta tiene una influencia limitada" (Van Der Heijden, Ibid.). Aquí, las influencias provienen de los actores sociales de envergadura, como son las grandes empresas, cuyas maniobras comerciales, financieras o laborales afectan a las empresas pequeñas. También pertenecen al entorno contextual los estatutos fiscales, laborales, ambientales, de propiedad intelectual y de protección al consumidor que establecen los gobiernos (federal, estatal y municipal) en su función reguladora, necesarios para cumplir su función social a través de la recaudación de impuestos; así como las acciones de fomento al desarrollo empresarial a través de programas de financiamiento, incentivos fiscales y comerciales para atraer a las empresas o crear nuevas en ciertos polos de desarrollo articulados a las politicas públicas. Finalmente, al entorno contextual pertenecen los aspectos geográficos, poblacionales y sociales de una región en particular donde se encuentra asentada la empresa (vialidades, urbanización, redes ferroviarias, aeropuertos), seguridad social, certeza jurídica y prácticas ético-culturales generalizadas en la población del lugar.

Actualmente, en función de la competitividad, también se esquematiza el entorno empresarial a través de diversos tipos de índices económicos, de los que destacan los llamados "indices de competitividad" regional, con el fin de evidenciar el grado de "fertilidad" que caracteriza a un medio geopolítico particular para realizar actividades empresariales. Este nivel de fertilidad influye decisivamente en la competitividad de las empresas locales y, por consiguiente, en la de sus productos. En contraste, otros enfoques muestran que la competitividad de las regiones es más bien resultado de "una 
red de acuerdos y actividades productivas y financieras entre las empresas transnacionales" (De Rivero, 2001:63).

Por la relevancia que tiene para la empresa comprender el dinamismo de su entorno, una función primordial de sus directivos radica en lograr la correcta interpretación y, en lo posible, una certera anticipación del cambio en las variables de particular influencia, con el fin de aprovechar oportunidades y prevenir amenazas. En este sentido, la técnica de análisis de riesgos enfatiza en los del entorno que "surgen cuando existen fuerzas externas que pueden afectar la viabilidad del modelo de negocio de la empresa, en particular, cuando dichas fuerzas afectan las variables que definen los objetivos y estrategias del modelo" (Deloitte \& Touche, 2003:115). El monitoreo de índices (económicos, financieros, laborales, comerciales, sociales y de riesgo) y el uso de técnicas para analizar tendencias y escenarios, son las herramientas utilizadas hoy en día en el reto planteado por el entorno convulso, que ha obligado a la empresa a operar bajo modelos de negocios flexibles, enmarcados en estrategias de diferenciación.

\section{USOS O ACEPCIONES (ACLARACIONES)}

Local. (Del lat. locãlis). 1. adj. Perteneciente o relativo al lugar. 2. adj. Perteneciente o relativo a un territorio, a una comarca o a un país. 3. adj. Municipal o provincial, por oposición a general o nacional.

Regional. (Del lat. regionālis). 1. adj. Perteneciente o relativo a una región.

Nacional. 1. adj. Perteneciente o relativo a una nación. 2. adj. Natural de una nación, en contraposición a extranjero. U.t. c. Global. 1. adj. Tomado en conjunto. 2. adj. Referente al planeta o globo terráqueo.

La categorización que se hace del concepto "entorno empresarial" como regional, local, nacional y global, reflejan tanto el alcance geográfico de operaciones como el modelo de negocio de la empresa. La intención de una empresa por ampliar el mercado hacia una categoría mayor (por ejemplo de operaciones locales a regionales), la coloca frente a retos complejos, como son el conocimiento y cumplimiento de nuevas exigencias arancelarias, culturales, climáticas, comerciales y normativas. Cuando se habla del entorno empresarial global como el nuevo ámbito obligado de las empresas ante la apertura comercial mundial, surge el conflicto para las empresas locales de menor envergadura en todas las regiones del planeta, por su imposibilidad de competir, a veces incluso en su propio mercado local, contra las grandes industrias transnacionales que llegan a todas las regiones del orbe con acciones apabullantes (Bauman, Zygmunt, 2010).

\section{SinÓNIMOS}

Ambiente empresarial.

Entorno transaccional: "campo de juego", ámbito de acción, sector industrial.

Entorno contextual: macro ambiente, contexto empresarial.

\section{ANTÓNIMOS}

Ambiente interno, medio interno, ámbito organizacional. 


\section{EJEMPLOS}

Uno representativo de la influencia de los factores del entorno empresarial en la competitividad y la calidad de vida de las regiones, se observa claramente al comparar los costos de servicios para operar como empresa en México (energía eléctrica, gas, impuestos, etc.), con sus respectivos en las economías desarrolladas.

Véase: Actores de diseño, Macroeconomía-Microeconomia y Ambiente

\section{Bibliografía}

AcKoff, R. (2002), El paradigma de Ackoff: una administración sistémica, México: Limusa Wiley.

BARMAN, Zygmunt (2006), Vida liquida, Madrid: Espasa Libros.

CAPUz, Salvador (1999), Introducción al proyecto de producción. Ingeniería concurrente para el diseño de producto, España: Universidad Politécnica de Valencia.

De RIVero, Oswaldo (2001), El mito del desarrollo. Los paises inviables del siglo XXI, México: Fondo de Cultura Económica.

DeloitTe \& Touche (2003), Administración integral de riesgos de negocio, México: Instituto Mexicano de Ejecutivos de Finanzas.

Dossier (2004), Manual de escenarios, Ginebra:

Centro Europeo para el Desarrollo de la Formación Profesional.

GARCÍA, Nestor (2009), Consumidores y ciudadanos. Conflictos multiculturales de la globalización. México: Debolsillo.

HERAs, Iñaki (2001), 100 Cuestiones de interés sobre economía y empresa, Madrid: Ediciones Pirámide. Osorio, Jaime (2000), Fundamentos del análisis social. La realidad social y su conocimiento, México: UAM- Fondo de Cultura Económica. Schultze, Charles (1980), El uso público del interés privado, México: Editores Asociados. VAN der Heijden, K. (1998), Escenarios, México: Panorama Editorial.

\section{Gestión del diseño industrial}

\section{DEFinición Diccionario RAE (DENOTACIÓN)} Gestión (Del lat. gestro, -ōnis). 1. f. Acción y efecto de gestionar. 2. f. Acción y efecto de administrar.

\section{DESARROLLO O CONSTRUCCIÓN DEL CONCEPTO} Gestion, administración y management son términos que con frecuencia escuchamos, sin embargo, los diseñadores no tenemos muy claro qué significa cada uno de ellos, ni la importancia que tienen en el diseño industrial. A fin de poder establecer las diferencias y similitudes que hay entre estas áreas comenzaremos por analizar su raíz etimológica. Gestión, proviene del latín gestı̌o,-ōnis que significa: "la acción de llevar algo a cabo"; usado como verbo, este sustantivo se refiere a "hacer diligencias para la consecución de algo" o, a "la tramitación de un asunto". En el caso de administración, la palabra proviene del latín administrare y es entendida como la capacidad de manejar los recursos de una empresa o institución, por lo que la administración puede darse tanto en el ámbito público o privado.

Por su parte management, es un término en inglés que tiene su origen en el francés manáge, y se usa para describir el acto de controlar y 
dirigir por quien está en la posición de responsabilidad más alta dentro de una empresa. Aun cuando la palabra administración (administration) también existe en inglés, su diferencia con management reside en que es usada para referirse al liderazgo que ejercen los directivos de alta gerencia.

Para un mundo globalizado y altamente competitivo el diseño debe ser gestionado, administrado y tomado en cuenta por los directivos de las empresas. El diseño debe ser estratégico para todas las compañías, sean pequeñas, medianas o grandes, y sin importancia del sector o ramo de actividad en que se desenvuelvan; ya que todas las empresas requieren del diseño para crecer o mantener su posición.

El reconocido historiador del diseño, John Heskett (2002), ha sido enfático al mencionar: "las grandes empresas fueron pequeñas empresas con grandes ambiciones". Haciendo una comparación de las principales actividades de la gestión, la administración y el management, encontramos que en diferentes grados las tres comparten las siguientes cinco tareas: planear, organizar, liderar/motivar, coordinar y controlar. Pero ¿cómo puede un diseñador incorporar estas actividades en su quehacer y aun desde la perspectiva del freelance o diseñador independiente? A continuación se aborda cada una de las actividades y su relación con el diseño.

La etapa de planeación es fundamental ya que en ella se establecen las direcciones y estrategias para llegar al punto deseado. En otras palabras, debemos reflexionar sobre: ¿a dónde queremos ir? y ¿cómo vamos a llegar ahí? La planeación es una actividad del management del diseño. Organizar, aquí el diseñador debe valorar y medir todos los recursos disponibles a fin de alcanzar sus metas. Los recursos a considerar deben ser humanos, tecnológicos y financieros, entre otros. Organizar es principalmente una tarea de la administración del diseño.

Liderazgo, un líder no es únicamente a quien todos siguen, sino quien los inspira. Un líder debe motivar, convencer y vender; esto último dos veces, y es que hay que vender interna y externamente. El escepticismo y la apatía son enemigos a vencer dentro y fuera de cualquier departamento o despacho de diseño. Liderar es una actividad esencial en el management del diseño.

Coordinar, implica ejecución y seguimiento de cada una de las tareas del proyecto de diseño, desde la planeación hasta la entrega y evaluación. La coordinación es una actividad tanto de la gestión como de la administración del diseño.

Control. Todas las actividades implican un grado de incertidumbre, mucho de ello ocasionado por la misma imperfección del ser humano, no obstante, la sistematización y versatilidad del proceso de diseño puede permitir un amplio control del proyecto de diseño. El control, por lo tanto, es una actividad implícita en la gestión, la administración y el management del diseño.

El prestigioso Instituto para la Administración del Diseño (Design Management Institute, DMI), ha señalado que el desarrollo, organización, planeación y control de recursos enfocados en aspectos centrales efectivos de productos, comunicaciones y ambientes son tareas fundamentales de esta disciplina, y el diseñador debe 
coordinar, planear y evaluar el proceso de diseño a fin de desarrollar un producto innovador que satisfaga las necesidades de los usuarios y genere una ganancia para las empresas.

El profesor británico Robin Roy (1990) define la administración del diseño como la disciplina que planea y coordina las actividades de crear, desarrollar y lanzar un nuevo producto o servicio al mercado, mientras que M. Oakley (1984) ha sugerido que la planeación y el desarrollo del brief, así como monitorear y evaluar las actividades de diseño son las principales características de un modelo de administración del diseño.

El entorno actual demanda diseñadores con sólidas habilidades de diseño, pero también con amplios conocimientos de administración donde el manejo de recursos financieros, humanos y tecnológicos es importante para el correcto desarrollo del proyecto de diseño, actividad que sin duda requerirá de una intensa labor de gestión con todas y cada una de las etapas y partes involucradas, sin embargo, todo lo anterior sólo será posible si existe un amplio compromiso de la alta gerencia en el management del diseño, donde éste sea visto como un elemento estratégico de competitividad, que puede ayudar a la obtención de resultados empresariales favorables, acciones que replicadas en una amplia escala podrían generar la competitividad de las empresas mexicanas, lo que sin lugar a dudas desencadenaría un impacto positivo en la economia de nuestro país.

\section{USOS O ACEPCIONES (ACLARACIONES)}

A fin de evitar mayores confusiones, cabe hacer una diferenciación genérica; gestor es aquel que se encarga de hacer los arreglos necesarios para la obtención o cumplimiento de objetivos, mientras que un gerente es quien organiza y emplea los recursos de una empresa para alcanzar las metas propuestas por la dirección.

\section{SINÓNIMOS}

Tramitar, diligenciar, ejecutar, dirigir, administrar, resolver, encargar, mandar, negociar.

\section{ANTÓNIMOS}

Desorganización, obstaculizar.

\section{EJEMPLOS}

En un contexto amplio es correcto decir que un administrador web es el responsable del mantenimiento y gestión de una página de internet.

\section{BiBLIOGRAFÍA}

Baxter, Mike (1999), Product Design, A practical guide to systematic methods of new product development, England: Chapman and Hall.

BESSANT John (2002), "Why design?", in Bruce Margaret and John Bessant (ed.), Design in Business Strategic Innovation Through Design, England: Prentice Hall.

BorJa de Mozota, B. (2003), Design management, using design to build brand value and corporate innovation, New York: Allworth Press

BRUCE, A. and Langdon, K. (2000), Strategic Thinking, London: Dorling Kindersley.

HESKETT John (2002), Toothpicks and Logos, Design in Everyday Life, England: Oxford University Press. OAKLEY, M. (1984), "Managing product design, London: George Weidenfeld \& Nicolson Limited. 


\section{Innovación y competitividad}

\section{Definición Diccionario RAE (DENOTACIÓN)}

Innovación (Del lat. innovať̆o, -ōnis). 1. f. Acción y efecto de innovar.

Innovar (Del latín innovāre, que significa: 1. Cambio que introduce novedades. 2. f. Creación o modificación de un producto, y su introducción en un mercado.

\section{DESARROLLO O CONSTRUCCIÓN DEL CONCEPTO}

El diseño, según Herbert A. Simon (1996) pretende cambiar una situación existente hacia una preferible, lo cual puede implicar tanto una mejora como una novedad, o bien ambas. Con base en esto, la innovación está presente en la praxis del diseño industrial ya que el diseñador "de acuerdo a los requerimientos" puede realizar diseño de productos e innovación de productos. La primera se refiere a la capacidad que tiene el diseñador de configurar productos, lo cual no necesariamente implica una novedad, pero sí un cambio; mientras que la innovación de productos implica novedades en cuanto al concepto, parte o totalidad del nuevo producto (Robin, 1990). La razón para desarrollar el diseño o la innovación de un producto obedece a lo planteado en el brief de diseño. Es importante aclarar que en un producto pueden converger tanto una reconfiguración como una novedad. Lo anterior se puede apreciar en el sector automotriz, o de electrodomésticos, por mencionar sólo algunas de las áreas que se presentan en la práctica del diseño industrial.

La innovación no compete únicamente al desarrollo y aplicación de alta tecnología sino a nuevas formas de pensar, hacer y ver las cosas, así como de ideas revolucionarias que contienen valor. John Kao (2007) ha definido la innovación como la capacidad de los individuos, empresas y naciones para crear continuamente su futuro deseado. Este autor extiende su definición al condicionar la innovación a la aplicación y generación de conocimiento en una serie de disciplinas, además de la ciencia y la tecnología, entre ellas el diseño, las ciencias sociales y las artes. La innovación va más allá del desarrollo de productos, ya que los servicios, experiencias y procesos puede ser innovadores también. Por lo tanto, la innovación está siempre en un estado de evolución, motivada de acuerdo con Buchanan (1992), por un interés social.

Que el diseño y la innovación sean determinantes en la capacidad de los individuos y las empresas, da pie a que estas disciplinas sean consideradas estratégicas en la competitividad de las naciones. Aunque por competitividad se puede entender la capacidad de dos o más personas de contender entre sí, aspirando unas y otras con empeño a una misma cosa; en el entorno empresarial se entiende la capacidad que tiene una empresa de ser productiva $\mathrm{y}$ ofrecer valor.

La gran mayoría de las empresas cuentan con tres áreas en su organización, la del director o dueño; la de producción o compras, y la de ventas o comercialización. Sin embargo, hay una nueva generación de empresarios que dada la apertura comercial buscan ser más eficientes por lo que amplían su base organizacional para afrontar mejor los nuevos retos de la globalización. Esta 
actitud y el éxito de sus operaciones los lleva a establecer una dirección general, un área de mercadotecnia, una de finanzas, una de producción y una de ventas. Por supuesto que la complejidad de cada negocio es diferente y la estructura puede variar o inclusive aumentarse, no obstante, el diseño está presente en cada una de las áreas en un mayor o menor grado.

Contrario a lo que se cree, la mercadotecnia no son ventas sino conocer las necesidades y deseos de la gente a fin de satisfacerlas, por tal motivo las actividades principales de un mercadólogo son el entendimiento del mercado, la generación de nuevos productos y servicios, así como su promoción, por lo que el diseñador puede contribuir al éxito de ésta tarea al ayudar en los estudios de mercado, el listado de requerimientos, el brief, la configuración del producto, los atributos del mismo, así como su empaque, identidad, página web, etcétera.

En la parte de ingeniería o producción, el papel del diseñador es vital al momento de configurar productos tangibles como un envase, una silla, un reloj, un juego de cubiertos, zapatos, el interior de un automóvil, los baños y asientos de un avión, entre otros muchos productos, su desempeño cobra mayor importancia al diseñar los productos que más interactúan con el usuario o cliente (Ulrich, 200o).

En cuanto al área de finanzas, la función del diseñador es crucial ya que éste es quien determina los materiales y proceso de producción o reproducción, lo cual tendrá un impacto en el costo y, por lo tanto, en el precio del objeto de diseño. Para el área de ventas el diseño también es estratégico, y es sabido que un mal empaque, instructivo, deficiente sitio web, asi como un servicio post venta son elementos suficientes para inhibir una compra y restarle competitividad a la empresa. No obstante, el papel del diseñador no se limita sólo a diseñar productos tangibles, sino que su actividad se extiende también al área de servicios. Imaginemos por un momento que sería de un banco sin la señalización adecuada o la forma y/o papelería correcta para una operación, y esto aplica tanto a la forma hecha de papel como a la forma virtual en el sitio web del banco.

Finalmente, para el área directiva el diseño debe ser estratégico y herramienta importante que puede alinearse con las estrategias de costo, segmentación y diferenciacion, entre otras (Porter, 1985). En los negocios la estrategia es necesaria para establecer el tipo de producto "tangible e intangible", que se desarrollará para su incursión en el mercado y la forma en que esto se hará, es decir, la estrategia determina el qué y el cómo. Es importante señalar que todas las empresas miden el éxito de su estrategia por los resultados financieros que obtuvieron a través de ésta (Bruce, 2000).

\section{USOS O ACEPCIONES (ACLARACIONES)}

Producto innovador es aquel que ofrece un nuevo concepto, en parte o en su totalidad.

Diseño de producto es aquel ofrece una reconfiguración de materiales.

\section{SINÓNIMO}

Novedad. 


\section{ANTÓNIMO}

Conservadurismo.

\section{EJEMPLOS}

El automóvil fue un invento que se volvió una innovación de transformación al cambiar la forma en que vivimos. La mayoría de los cambios anuales que se hacen a los autos son innovaciones incrementales, sin embargo, con la llegada de los autos eléctricos estos cambios se consideran innovaciones radicales. Es decir, los autos eléctricos son muy diferentes a los primeros autos basados en motores de combustión. En todos los casos se requirió del diseño ya que estas innovaciones por más radicales que fuesen necesitan tomar una forma que se adecue al uso que le dará el ser humano.

\section{Bibliografía}

BRUCE, A. y Langdon, K. (2000), Strategic thinking, London: Dorling Kindersley.

Buchanan, Richard (1992), “Wicked Problems in

Design Thinking", in Design Issues, Vol. 8, No. 2, 1992, pp. 5-21.

KAO, John (2007), Innovation nation, New York: Free Press.

PORTER, Michael, E. (1985), Competitive Advantage, New York: Free Press.

RoBIN, Roy (1990), Product design and technological innovation, England: The Open University, Milton Keynes.

Simon, H. A. (1996), The sciences of the artificial, Boston: MIT Press.

UlRICH Karl T. y Eppinger Steve D. (2000), Product design and Management, USA: Irwin McGraw-Hill.

\section{Planeación}

\section{Definición Diccionario RAE (DENOTACIÓN)} Planear. 1. tr. Trazar o formar el plan de una obra. 2. tr. Hacer planes o proyectos.

Plan. (De plano). 2. m. Intención, proyecto. 3. $\mathrm{m}$. Modelo sistemático de una actuación pública o privada, que se elabora anticipadamente para dirigirla y encauzarla. 4. m. Escrito en que sumariamente se precisan los detalles para realizar una obra.

\section{DESARROLLO O CONSTRUCCIÓN DEL CONCEPTO}

La relevancia de la planeación en el campo del diseño industrial radica en dos beneficios concretos. Por un lado, en la disciplina, la eficiencia y eficacia de la labor proyectual dependen en gran parte del dominio de esta técnica. Pero también, en un sentido más amplio - al ser la planeación un factor que intenta imprimir dirección a la participación de corto y largo plazo de los actores sociales (organizaciones) en un entorno particular-, atender los planes organizacionales permiten al diseñador detectar, articular y hacer converger los intereses para posibilitar iniciativas de diseño de envergadura

Con base en la definición de la Real Academia Española de la Lengua (RAE), se puede inferir que planear un proyecto de diseño industrial significa describir con precisión, antes de que suceda, cómo vamos a realizarlo, para que se logren los propósitos dados. La planeación es una actividad de carácter técnico y de naturaleza primordialmente racional, que culmina con la elaboración del documento llamado plan. 
Trazar el plan del proyecto a abordar enfrenta al diseñador a tomar una serie de decisiones anticipadas sobre los aspectos del mismo que considera clave para conducirlo hacia el resultado acordado, y con unos recursos previamente definidos. En otras palabras, la esencia de la planeación consiste en vislumbrar el plan para cambiar una situación actual inconveniente, pero conocida, por otra futura que se vislumbra como mejor, pero desconocida.

Por otro lado, a través del plan, los expertos en el tema pueden evaluar con facilidad la factibilidad de una propuesta de proyecto de diseño industrial, para asignarle o negarle recursos. De aprobarse ésta, el plan sirve para mantener en sintonía a todos los actores del proceso de diseño durante su ejecución, porque transparenta las metas particulares de las fases del proyecto, la organización del trabajo a lo largo de las mismas y la asignación de recursos en el tiempo. Además, el plan resulta un medio indispensable para comunicar detalles operativos importantes al interior del equipo de trabajo.

La complejidad de la planeación radica en la dificultad para tomar decisiones anticipadas que resulten acertadas en el futuro, porque estas decisiones se realizan con base en lo que el planificador vislumbra como correcto en el momento presente (del entorno, del equipo de trabajo, del problema). Con esta información el planificador define lo que supone como más conveniente para la situación futura (cuando se ejecuten estas actividades o, por ejemplo, cuando se use el producto diseñado). La experiencia acumulada a lo largo de años planeando un mismo tipo de proyectos aumenta la certeza de las predicciones; sin embargo, es justo en el caso contrario en el que la herramienta resulta más útil, pues en la sistematización de la técnica de planeación se incorpora la experiencia acumulada al respecto, de forma que puede ser trasmitida con claridad al diseñador inexperto. En otras palabras, las técnicas de planeación y el plan resultante, se convierten en un recurso que obliga al diseñador novato a reflexionar, como lo haria el experto, sobre los aspectos clave del proyecto

Como resultado, la planeación reduce de forma real, pero también aparente, la incertidumbre alrededor de todo proyecto de diseño. Aparente porque, además del efecto anteriormente descrito, tener un plan genera certeza en los actores del proyecto de diseño y del equipo de trabajo, quienes a través del plan perciben que el proyecto será abordado con orden y objetividad, incluso previendo opciones ante las posibles contingencias. Bajo las técnicas de planeación convencional, los principios de objetividad que sustentan las decisiones del planificador, requieren de información amplia, cuantificable, objetiva (obtenida por métodos rigurosos), como recurso necesario para tomar decisiones acertadas. Sin embargo, esta pretensión de certidumbre, real y aparente de la planeación se "tambalea" entre más dinámico y complejo se vuelva el entorno del proyecto, es en este caso donde la estrategia se ha posicionado en los últimos años como una herramienta eficaz que complementa los alcances de la planeación en la difícil tarea de dar direccionalidad 
TOMA... 204 CONCEPTOS CLAVE PARA LA FORMACIÓN DEL DISEÑADOR INDUSTRIAL • PARTE ॥

correcta a las iniciativas futuras de diseño de una empresa y de sus productos.

\section{USOS O ACEPCIONES (ACLARACIONES)}

Planificar" y "planear" son actividades intelectuales similares, pero la primera se relaciona más con una tarea a gran escala.

\section{SINÓNIMO}

Planificar.

\section{Antónimos}

Actuar, ser pragmático.

\section{EJEMPLOS}

Entre los aspectos importantes que se precisan en un plan del proyecto de diseño destacan: el alcance que tendrá el proyecto (metas y objetivos), las actividades a realizar detalladas, responsables de las mismas, la estimación de tiempos para realizarlas, la secuencia en que deberán ejecutarse, las relaciones entre las mismas, qué recursos se aplicarán en qué momento, así como vislumbrar las contingencias posibles y las opciones de solución que se estiman convenientes bajo la situación en que se desarrollará el proyecto. Si al plan de proyecto se incorporan los costos de realización, con frecuencia se le nombra: "Plan ejecutivo".

\section{Bibliografía}

AcKoff, Russell (2002), El Paradigma de ackoff. Una administración sistémica?, México: Limusa-Wiley. Burstein, David y Stasiowski, Frank (1991), Project Management for the Design Professional,
Editorial Whitney Library of Design. Instituto Latinoamericano de Planificación Económica y Social (2006), Guía para la presentación de proyectos, México: Siglo XXI. KERZNER, Harold (2003), Project management. A systems approach to planning, Scheduling and Controlling", New Jersey: John Wiley and Sons. MAtus, Carlos (2001), Estrategia y plan, México: Siglo XXI editores.

RoszAK, Theodore (1990), El culto a la información. El folclore de los ordenadores y el verdadero arte de pensar, México, Grijalbo.

\section{Toma de decisiones en diseño}

\section{Definición Diccionario RAE (DENOTACIÓN)}

Decidir. (Del lat. decidĕre, cortar, resolver). 1. tr. Cortar la dificultad, formar juicio definitivo sobre algo dudoso o contestable. Decidir una cuestión. 2. tr. Resolver (tomar determinación de algo). U. t. c. prnl. 3. tr. Mover a alguien la voluntad, a fin de que tome cierta determinación.

Decisión. (Del lat. deciš̌o, -ōnis). 1. f. Determinación, resolución que se toma o se da en una cosa dudosa.

\section{DESARROLLO O CONSTRUCCIÓN DEL CONCEPTO}

Tomar decisiones es una responsabilidad inherente al ejercicio del diseño industrial, que se realiza profesionalmente en diversos niveles o cargos de la jerarquía organizacional y de la propia (el equipo de diseño que aborda un proyecto). Diseñar un producto nuevo en la empresa requiere de una deliberación cuidadosa que 
genera, a veces de manera informal, lo que se denomina un "sistema de decisiones" especifico, cuyos lineamientos se irradian a todas las decisiones del proyecto. Así, el diseño de un producto particular llega a ser, entonces, el resultado de un procedimiento básico de toma de decisiones; por esto, algunos métodos consideran a esta acción como un hilo conductor del proceso de diseño.

Sin embargo, a pesar de su relevancia - que radica en que una decisión de diseño aún mínima, tiene un efecto exponencial en aspectos productivos, comerciales, financieros, y de mercado-, la toma de decisiones es con frecuencia desatendida como tema de aprendizaje durante la formación del diseñador. Una razón probable es que se piensa que definir algo dudoso requiere sólo de elegir una opción entre varias disponibles usando el sentido común. Pero la complejidad cada vez mayor de factores que intervienen en los proyectos de diseño, nos orilla a atender esta tarea asistidos de herramientas. También se cree que para tomar decisiones certeras lo que falta es información conveniente. Si bien disponer de ella facilita el proceso, no garantiza decisiones acertadas, como lo expresa muy bien el economista Kofman (2003:25): "la información es valiosa sólo en tanto es interpretada por el modelo mental del oyente" En principio, las buenas decisiones son las que nos acercan a los objetivos del proyecto, sin embargo, en el campo del diseño se reconoce que existen diversas respuesta correctas para cada situación dudosa.

Conceptualmente, los elementos básicos al tomar una decisión son: la situación dudosa por decidir, la información y tiempo disponibles para tomar la decisión, lo que se pone en riesgo con la decisión, las alternativas de solución posibles y quién o quiénes toman la decisión. Vista bajo otro ángulo, en la toma de decisiones se observan factores objetivos, subjetivos, pautas que definen nuestra particular forma de abordar las decisiones y efectos posibles. Al respecto, un enfoque que destaca el modelo de toma racional de decisiones, plantea las siguientes etapas para maximizar los resultados de quien realiza esta tarea (Harrison, 1999:132):

- Definir el problema

- Identificar los criterio de decisión

- Dar peso a los criterios

- Desarrollar aiternativas

- Evaluar las alternativas

- Elegir la mejor alternativa

En el extremo de este enfoque, se plantea la posibilidad de tomar decisiones asistidos por modelos matemáticos, a través de técnicas como la investigación de operaciones o de uso de métodos cuantitativos para este efecto, de gran utilidad al diseño cuando se busca optimizar los aspectos técnicos del nuevo producto. Sin embargo, este enfoque muestra inconsistencias cuando aún se están decidiendo la totalidad de factores que conformarán al nuevo producto, en especial, los aspectos subjetivos relativos a las funciones de uso y expresivas del producto. La influencia del factor humano en la toma racional de decisiones la expresa Kofman (2003:41) de la siguiente manera: "el supuesto de racionalidad es tan crítico como inflexible... 
eso quiere decir que si uno relaja el supuesto aunque sea un poquito -la gente es irracional una que otra vez-, la mayoría de los modelos pierden todo poder de predicción".

Por esta razón, Robbins propone el concepto de racionalidad acotada, como un procedimiento más útil en las organizaciones: "los individuos toman decisiones elaborando modelos sencillos en los que sitúan las características esenciales de los problemas, sin captar toda su complejidad" (Robbins, 2004:135). Con anterioridad los experimentos de Kahneman (1971) profundizaban sobre este mismo concepto introduciendo el factor heurístico en la toma de decisiones, que lo expresa como: "los humanos no solemos emitir juicios o tomar decisiones siguiendo procedimientos totalmente racionales o estadísticos sino empleando los denominados heurísticos. Éstos constituyen una especie de "atajos cognitivos", estrategias no formales para resolver problemas, que permiten la emisión de juicios. Es obvio que existen ventajas adaptativas en su empleo, como es la velocidad a la hora de tomar decisiones..., por otro lado, es cierto que muchas veces nos llevan a soluciones adecuadas y correctas, sin embargo, dichos heurísticos son estrategias inexactas que pueden dar lugar a sesgos" (Álvares, 2007).

Un factor difícil de controlar en la toma de decisiones son las pautas y creencias de las personas que tienen la responsabilidad de decidir, porque éstas definen en mucho la percepción sobre la situación dudosa por decidir y sobre todo, la magnitud y los efectos de la decisión. Por ello es que las situaciones complejas dentro de las organizaciones se dirimen con decisiones consensuadas, las cuales actualmente retoman el factor intuitivo, cada vez más reconocido en el ámbito organizacional como un complemento del factor racional.

La influencia que diversos actores tienen en la toma de decisiones a lo largo de un proyecto de diseño industrial, exige al diseñador la capacidad para argumentar con solidez las decisiones que se han tomado desde el diseño para el logro de los objetivos del proyecto, y así mantener vigentes los atributos del nuevo producto que el diseñador plantea, a pesar de otros puntos de vista. En este sentido, al observar el proceso de diseño como un proceso de toma de decisiones, emerge un aspecto fundamental en la formación del diseñador: la naturaleza de las decisiones en diseño. El hecho de que el alumno funja simultáneamente a lo largo de un proyecto, indistintamente como director, gerente, jefe $\mathrm{u}$ operario técnico de la organización, o en rangos de distinto nivel en el equipo de diseño (Master, Senior, Junior, Trainee, incluso como operario técnico), tiene el beneficio didáctico de enfrentarlo a tareas diversas de su profesión; pero también, tiene el inconveniente de que fomenta una toma de decisiones descontextualizada, es decir, sin comprender la naturaleza, condicionantes y efectos de cada tipo de decisión, en relación con el total de la organización. Así, la única directriz que marca sus decisiones es la maximización del desempeño del producto abordado (seguridad, confort, estética). Esta responsabilidad organizacional de decidir a distintos niveles en la jerarquía, integrando las exigencias de las áreas, nos 
lleva a considerar que las decisiones "óptimas" son en realidad las decisiones aceptables, porque son las que equilibran satisfactoriamente el total de las exigencias. Herbert Simon plantea con claridad esta práctica empresarial: "Ante la compleja realidad, la empresa prefiere procedimientos que hallen respuestas suficientemente buenas a cuestiones cuyas respuestas optimas son desconocidas. Dado que en el mundo real la optimización, con o sin ordenadores, es imposible, el actor económico real es, de hecho, un satisfictor, una persona que acepta alternativas "bastante buenas" no porque se conforme con menos, sino porque no tiene otra alternativa" (Simon, 1974).

\section{SINÓNIMOS}

Decidir, dirimir.

\section{ANTÓNIMOS}

Inmovilismo, duda.

\section{EJEMPLOS}

En el campo de los negocios las decisiones sobre diseño de nuevos productos generan deliberaciones cuidadosas entre directivos de diversas áreas de la empresa, que apuntan a evitar efectos letales en las finanzas. Asimismo, durante el proceso de diseño, tomar decisiones sobre aspectos neurálgicos del proyecto y del producto que se diseña, resulta ser una actividad de convergencia de fines entre actores y especialistas de diversas áreas con intereses distintos. De forma que, las decisiones "óptimas" son en realidad las que cumplen convenientemente todos los requisitos múltiples de la empresa. Al respecto, una práctica recomendable en la formación del diseñador, es el discernir sobre el sistema básico de decisiones que rige su proyecto, de forma que sean evidentes las repercusiones de sus decisiones y los beneficios.

\section{Bibliografía}

Álvares, Carlos (2007), "Kahneman y las creencias erroneas", véase:

http://forum-psicologos.blogspot.com

HARRISON, E. F. (1999), The Managerial Decision-

Making Process, Boston: Houghton Mifflin.

KERZNER, Harold (2003), Project Management. A Systems Approach to Planning, Scheduling and Controlling. New Jersey: John Wiley and Sons Inc.

Kofman. Fredy (2003). Metamanagement, nueva conciencia de los negocios, Tomo 1: Principios. México: Ediciones Garnica.

RoBbINS, Stephen (2004), Comportamiento organizacional. México: Pearson- Prentice Hall. 